\title{
Reescritura de Guimarães Rosa por Rinaldo de Fernandes: entre A hora e vez de Augusto Matraga e Grande sertão: veredas
}

\begin{abstract}
Descobri o que os escritores sempre souberam (e nos disseram muitas e muitas vezes): os livros sempre falam sobre outros livros, e toda estória conta uma estória que já foi contada.

Umberto Eco
\end{abstract}

Estabelecer um diálogo intertextual com um ficcionista do porte de Guimarães Rosa é tarefa nada fácil. Reinventar enredo e destino dos personagens do contista de Sagarana, obra de estreia $^{2}$ do escritor mineiro, que surge no panorama de nossa literatura como "marco decisivo da evolução da prosa de ficção brasileira" (COUTINHO, 1991), constitui um temerário desafio. Reescrever a trajetória de seus protagonistas e coadjuvantes, suplementando significativamente a matéria e a forma da narrativa rosiana, aponta para um talento inusitado em ficcionistas iniciantes. Sobretudo se o texto reescrito for "A hora e vez de Augusto Matraga", considerado pela fortuna crítica do autor como "a peça melhor realizada do livro", no dizer de Álvaro Lins (1991, p.241), ou a "obra prima" da coletânea de 1946, como o saúda o autor de Tese e antítese, em pioneiro ensaio, escrito, a exemplo do artigo de Lins, no mesmo ano de publicação da obra, onde vaticina o êxito literário do "conto" (o texto é formalmente uma novela), incluindo-o doravante "entre os dez ou doze mais perfeitos da língua" (CANDIDO, 1991, p.247).

Mais de meio século depois, Rinaldo de Fernandes assume o desafio e... o risco do dialogismo e publica ${ }^{3}$ o conto "Sariema", relendo ludicamente no seu texto o intertexto de Rosa. O procedimento básico adotado nessa releitura é o da mudança de foco narrativo, responsável

\footnotetext{
${ }^{1}$ Professora Titular da Universidade Federal de Pernambuco. E-mail: coordletras@ufpe.br.

${ }^{2}$ Embora o autor já tivesse publicado anteriormente, em periódicos, alguns contos e concorrido em 1936 e 1937 a prêmios literários com um volume de poesia, Magma, e uma encadernação de Contos, gênese de Sagarana. Ver a propósito: LIMA, Sônia Maria van Dijck. Escritura de Sagarana. São Paulo: Navegar, 2003.

O presente ensaio baseia-se na seguinte edição da obra: ROSA, João Guimarães. "A hora e vez de Augusto Matraga". In: Sagarana. 6a ed. Rio de Janeiro: José Olympio, 1964, pp. 319-365. E Grande sertão: veredas. 13aed. Rio de Janeiro: José Olympio, 1979. Nas citações do corpus, o primeiro livro será mencionado entre parênteses pela sua inicial. 3 Publicado originalmente no jornal literário Rascunho, de Curitiba/PR, em novembro de 2004. Republicado em: FERNANDES, Rinaldo de. O perfume de Roberta (contos). Op. cit., pp.157-169. Daqui por diante a referência à coletânea será feita pelas suas duas últimas iniciais.
} 
pelas novas configurações de personagens, fábula e trama ${ }^{6}$ da novela matriz. "A hora e vez de Augusto Matraga" é narrada em terceira pessoa, por um narrador anônimo, não dramatizado na cena diegética, cujo relato incide principalmente sobre uma figura masculina, representante do "mandonismo local", o fazendeiro Augusto Esteves, das Pindaíbas, ou Nhô Augusto, "o homem", e seu "rito de passagem" para a posição "liminar" de Matraga.

"Sariema" conta, ou melhor, reconta a mesma e outra história sob a ótica de uma narradora em primeira pessoa $^{8}$, que, ao contrário da posição secundária e subalterna vivida na narrativa que lhe serve de paradigma, passa a participar da diegese como protagonista, mudança de estatuto evidenciada já pelo título do conto. Assim, a partir do deslocamento do ponto de vista, o conto introduz uma diferença fundamental em relação à narração e à matéria narrada no primeiro texto. Traz para o proscênio uma voz feminina praticamente recalcada pelo narrador rosiano. É, portanto, uma personagem "ex-cêntrica" no intertexto de referência (no sentido de "off-centro" e de descentralizada (HUTCHEON, 1991, p.170) - mulher, prostituta e desfavorecida socioeconomicamente - que assume agora uma posição de destaque e passa a narrar e pontuar a sua versão dos fatos. E ao fazê-lo, retraça seu destino e sua trajetória, não se submetendo mais passivamente à voz do sujeito da enunciação da novela anterior, nem ao julgamento machista da comunidade sertaneja que a discrimina e reifica como "prenda" arrematada em leilão por Nhô Augusto e zoomorfizada sob o epíteto que lhe serve de estigma no mundo rural recortado por Guimarães Rosa.

Ao contrário, ao assumir a palavra, vai mostrar que pode transmudar sua vida e redimensionar a estória, diferentemente da Sariema da outra narrativa, cuja única reação diante da prepotência masculina é a ameaça de choro e a atitude de rendição.

A reivindicação à fala e ao ato de contar ocorre desde o início da narração, onde a personagem recorre às lembranças de infância para caracterizar uma peculiaridade sua: a de imitar - por "mugangas" e palavras - pessoas da família e aves: "Pio de pássaro, pica-pau, periquito, pombo. Perdiz, pato, peru - a peste” (PR, p. 157). A arte da imitação, assinalada sobretudo, por

\footnotetext{
6 Utilizam-se os termos fábula e trama no sentido que lhes confere TOMACHEVSKI, B. "Temática". In: EIKHENBAUM et all. Teoria da literatura: formalistas russos. Porto Alegre: Globo, 1971, pp. 169-204. O primeiro designa a história narrada, "o conjunto de acontecimentos ligados entre si que nos são comunicados no decorrer da obra"; o segundo a maneira de narrá-la ficcionalmente: "o modo pelo qual as coisas que acontecem se organizam na narrativa". 7 Ver a propósito: QUEIROZ, Renato da Silva. "Matraga, seu pai, seu filho”. In: http://www.imaginário.com.br. Acesso em 29/10/2005 e MATTA, Roberto da. "Augusto Matraga e a hora da renúncia". In: Carnavais, malandros e heróis: para uma sociologia do dilema brasileiro. Rio de Janeiro: Zahar, 1979, pp. 36-259.

${ }^{8}$ A distinção entre primeira e terceira pessoa por si só não é relevante. Importa, sim, a mudança de estratégias narrativas correlacionadas a tais categorias. Segundo afirma BOOTH, W. (A retórica da fição. Trad. de Maria Tereza Guerreiro. Lisboa: Arcádia, 1980, p. 166): "Dizer que uma história é contada na primeira ou terceira pessoa nada diz de importante, a menos que sejamos mais precisos e descrevamos o modo como qualidades particulares de cada narrativa se relacionam com efeitos específicos”. É justamente essa estratégia retórica que se busca apreender na abordagem comparativa dos dois textos em questão.
} 
analogia à espécie de ave que se caracteriza por tal atributo, o "papagaio", distingue positivamente a protagonista, em contraposição ao epíteto pejorativo de Sariema, com que é designada pelos homens do meio rural onde se insere no contexto de "A hora e vez de Augusto Matraga". Senhora dessa arte, a narradora-protagonista toma a palavra e conta - imitando também aqui o modo narrativo de um outro narrador de Guimarães Rosa, Riobaldo - a um interlocutor de fora (provavelmente da cidade) e estrategicamente mudo, como o de Grande sertão: veredas - o sucedido, conforme viveu e experimentou: "Você, que não é dessas bandas, que anda só de passagem. Você se acocore aí - aconteceu" (PR, p. 157).

À semelhança do aludido romance, o contexto da interlocução pressupõe um colóquio sem que a fala do interlocutor seja diretamente representada na cena textual, conforme se pode constatar do excerto transcrito, onde a narradora procura certificar-se da recepção do relato junto àquele a quem narra a sua história: “Tá gostando do que digo? Só vai saber porque há uns dois meses estou aqui neste casebre (...), caída nesta esteira, com esses ferimentos fechando, e se me ouvir... Ouve? Quer saber como eu vim parar aqui no Tombador?” (PR, p. 159). Na fala de Sariema, como na de Riobaldo, a pessoa e a vOz do outro são subtraídas do texto e subtendidas apenas pelo "reflexo no relato", para utilizar as expressões de Roberto Schwarz, caracterizando a relação dialógica entre o presumido pactário do romance e seu parceiro de prosa. Relação que o ensaísta classifica de “monólogo inserto em situação dialógica” ou "situação dramática” (SCHWARZ, 1981, p.38).

No texto de Rinaldo essa interlocução reflexa pode ser melhor configurada na seguinte passagem, onde as respostas e reações do forasteiro ouvinte são apenas deduzidas da voz de Sariema: "Uai! Os olhos assim tremendo? Sono? Tem, sim, medo de briga" (PR, p. 158). E ainda nesse outro entrecho: "Hum? Tenho mais ninguém no mundo, não. Só uma prima. Vou atrás dela, mais adiante...” (PR, p. 161). E, finalmente, na réplica da narradora, por onde se deduz a curiosidade do interlocutor pelo final da história: "Hein? Como foi o fim? Apois ficamos ali (...)" (PR, p. 167). Tem-se, portanto, aqui o típico “diálogo visto por uma face”, termos aplicados ainda por Roberto Schwarz à conversa do ex-jagunço com o interlocutor letrado nas páginas de Guimarães.

Ao encampar a técnica da encenação dramática de Grande sertão: veredas, "Sariema" encampa simultaneamente a "memória épica" e, à dicção oral dos tradicionais contadores de estórias, os narradores arcaicos benjaminianos, responsáveis pela transmissão/retransmissão dos relatos oralmente repassados, procedimento narrativo que é magistralmente exemplificado na voz de Riobaldo e alimenta, de resto, toda a produção ficcional do escritor de Cordisburgo. Inserindo na versão da protagonista não apenas os acontecimentos vividos e presenciados por ela, mas os que lhe chegam pela "boca do povo", "testemunha ocular dos fatos", o conto evidencia o circuito de 
comunicação estabelecido entre a figura da narradora e os habitantes da comunidade sertaneja, que se erigem eventualmente em narradores anônimos.

Vê-se isso no trecho onde Sariema diz ao forasteiro de que maneira se inteirou do episódio relativo ao relacionamento entre Matraga e o jagunço seu Joãozinho Bem-Bem, tempos depois de Nhô Augusto ter sido surrado, marcado a ferro e dado como morto pelo Major Consilva, o inimigo político que lhe arrebata propriedades, capangas, honra e decreta sua exclusão da estrutura do poder local: "Soube depois que, aí, Joãozinho Bem-Bem e Nhô Augusto amarraram-se numa amizade besta, um admirando o outro" (PR, p. 159). O relato anônimo ouvido por Sariema, e repassado por sua vez ao interlocutor de fora, ilustra o processo de retransmissão das experiências nas comunidades artesanais, locus das narrativas marcadas pela oralidade. Segundo diz Benjamin (1986, p.210), "o narrador retira da experiência o que ele conta: sua própria experiência ou a relatada pelos outros. E incorpora as coisas narradas à experiência de seus ouvintes". Sariema narra sobretudo a partir de sua vivência dos fatos - afinal ela conta a sua história - mas também eventualmente pela assimilação do relato alheio (daqueles que presenciaram ou ouviram contar o desdobramento da história de Matraga). E se encarrega de repassá-lo adiante, assegurando para si a retransmissão do que lhe foi contado: "Para o ouvinte (...) o importante é assegurar a possibilidade da reprodução" (BENJAMIN, 1986, p.210).

No conto, de forma análoga ao romance, essa retransmissão se dá não pela eclosão autônoma das vozes do sertão, mas pelo seu embutimento na única voz condutora do processo narrativo.

Mesclando os dois processos acima comentados, a encenação dramática e as formas épicas dos relatos orais (forjados, obviamente, pela escrita e atrelados aqui - à maneira de Grande sertão ao único e ininterrupto "fluxo de fala" ${ }^{15}$, o da personagem central que narra a história ${ }^{16}$ ), o conto em foco retoma o fio da meada tecida em "A hora e vez ..." para dela extrair a matéria formadora de sua tecelagem, imaginariamente recriada.

A nova urdidura se caracteriza simultaneamente pela réplica e pela inversão dos eventos narrados no texto cujo protagonista é Matraga. A narradora Sariema inverte não apenas a sua

\footnotetext{
15 Ver também a propósito desse processo no romance de Guimarães Rosa, GALVÂO, Walnice Nogueira. “A linguagem e a fala". In: As formas do falso. São Paulo: Perspectiva, 1972, pp. 69-74.

16 Talvez por adotar no processo narrativo o modelo da tessitura romanesca e não o da novela de Rosa, cuja narração em terceira pessoa abre-se momentaneamente à representação direta de outras vozes, o conto de Rinaldo deixa de recuperar os vários registros orais do folclore e da arte popular disseminados, desde a epígrafe, ao longo de "A hora e vez...", tais como a velha cantiga da epígrafe, retomada no interior do texto, os provérbios, as melopeias dos cegos sertanejos, em suma, as várias manifestações estéticas e culturais que, na voz coletiva e anônima da comunidade rural, desvinculam-se da do narrador, comparecendo autonomamente como "persona" na fabulação novelesca a pontuar os episódios do enredo. Salvo engano, apenas o dito popular retomado por Nhô Augusto no episódio em que rejeita Sariema ("Você tem perna de manuel-fonseca, uma fina e outra seca") é resgatado na tessitura do conto. Ver ROSA, Guimarães. Op. cit., p. 322, e FERNANDES, Rinaldo de. Op. cit., p. 160.
} 
trajetória, mas a do personagem com quem contracena, modificando ainda o perfil e o percurso de outros figurantes da novela. Assume, através do ingresso no bando de seu Joãozinho Bem-Bem, o status de mulher guerreira (jagunça tal qual Riobaldo), em substituição ao estigma de "mulher-à-toa", na expressão do narrador da primeira história. A mudança de máscaras sociais opostas assinala também sua conversão de prostituta à esposa, papel assumido pelo casamento com Orósio, ele igualmente transmudado: de "capiauzinho mongo", cuja namorada lhe é arrebatada pelo manda-chuva local, a valente jagunço (profissão compartilhada com a smulher no mesmo bando de seu Joãozinho).

O novo estatuto do personagem masculino é coroado com a morte heróica dele na luta com Matraga em defesa da honra da mulher, vítima da violência sexual daquele personagem. De forma similar, o percurso de Sariema, culminando com o assassinato de Matraga, possibilita à figura feminina não só medir forças em luta aberta e em pé de igualdade com o homem que a ultrajara, humilhando-o dessa forma (a luta nessas condições por si só contraria o código de "homência" do sertão ${ }^{17}$ ), mas, sobretudo, vencê-lo, passando, assim, de mulher desonrada, à vingadora da própria honra, de objeto sexual a sujeito de suas ações.

As transformações ocorridas com a protagonista e seu companheiro caminham no sentido da aquisição de uma nova posição e identidade sociais a eles negadas pela estrutura coronelista fortemente hierárquica do meio rural. Vingando-se de Matraga, a mulher realiza individualmente uma "contraprestação social", "uma forma de reinterpretação da sociedade pelo indivíduo", conforme definição de Roberto da Matta (1979, p. 249). Devolve, assim, ao agressor e, por extensão, à sociedade, as ofensas e humilhações que não lhe foi dado revidar no enredo de "A hora e vez de Augusto Matraga". Reinventando um final glorioso para Orósio, ela fecha o ciclo da vingança iniciada pelo personagem na cena anteriormente dramatizada pelo narrador de Rosa, em que o capiau amarelo, sob o comando e proteção do major Consilva, vinga-se da desfeita empreitada pelo homem que lhe arrebatara prepotentemente a namorada, figurando como um dos coadjuvantes no processo de derrocada e morte simbólica do herói rosiano.

Cabe, no entanto, à mulher a vingança definitiva, concretizada, agora, no final do conto. Tal desfecho lhe possibilita uma nova qualificação social pela recusa do epíteto que a discrimina identitária e socialmente no arraial da Virgem Nossa Senhora das Dores do Córrego do Murici, onde fora leiloada sob os aplausos e apupos da população masculina: "Não tem mais nenhuma Sariema! Não tem mais, não" (PR, p. 167). O grito de vitória da protagonista ecoa, de forma irônica e paródica, com sentido inverso, portanto, em um outro grito de triunfo: o do Major Consilva, ao

\footnotetext{
${ }^{17}$ Basta constatar a relutância de Matraga em enfrentar a mulher armada a faca, sob o argumento de que isso não é digno de homem, só o fazendo, finalmente, para defender-se dos violentos golpes da protagonista.
} 
decretar no contexto de "A hora e vez...” a exclusão, como derrotado, de Nhô Augusto Esteves da estrutura de poder da oligarquia rural. Decreto repetido em coro por seus capangas (entre os quais se situa o capiau de Sariema), e interiorizado posteriormente pelo próprio protagonista: “- Não tem mais nenhum Nhô Augusto Esteves, das Pindaíbas, minha gente?!...”, “- Não tem não! Tem mais não!...” (S, p. 330).

Ao contrário, pois, do grito de Sariema, que rejeita uma identificação excludente e assegura seu lugar na engrenagem do sistema social pelo "gesto final de reciprocidade que a vingança fatalmente engendra" (MATTA, 1979, p.252), o do Major Consilva sela o "rito de passagem" de Nhô Augusto, da posição hierárquica de proprietário de terras e senhor de jagunços à "liminaridade" de Matraga, entendendo-se por esta, de acordo com Renato da Silva Queiroz, na esteira de Matta, “o período de margem” no qual é lançado o personagem após a desmoralização pública, o "limbo (...) em que não se está verdadeiramente vivo nem morto" ${ }^{20}$, longe de seu espaço de origem e impossibilitado de recuperar seu lugar no sistema socioeconômico e político de onde proveio. Situação, em suma, característica “(...) daqueles momentos prolongados em que o transitante, tendo deixado a posição anteriormente ocupada na estrutura de seu grupo, não foi ainda reintegrado, não lhe sendo permitido, pois, também conforme Queiroz, "novo status na mesma estrutura".

Acompanha o ritual de passagem do herói de Rosa a perda do nome próprio que designa sua alta posição social na hierarquia do poder, Nhô Augusto Esteves, ou mais significativamente, Nhô Augusto, o homem - nome classificatório "composto de uma forma de prestação de senhorio (...) altamente marcado dentro do sistema de poder de sua comunidade" (MATTA, 1979, p.245) e a subsequente adoção do epíteto Matraga, compatível com a situação liminar em que se encontra. A frase de abertura da novela já aponta para essa transmutação social semantizada pela mudança de nome: "Matraga não é Matraga, não é nada" (S, p. 319). A radical troca de papéis sociais e de nomes se dá, aí, portanto, num movimento simétrico inverso àquele que caracteriza a rejeição do epíteto pejorativo de Sariema, no conto em exame.

Através da "condição jagunça", com várias mortes nas costas, tanto Sariema como Orósio reatualizam a imagem pública do "bandido social", na sua vertente de "bandido vingador", de que fala Hobsbawm. Imagem alimentada pelo próprio imaginário rural a seu respeito: aquele cujo uso da violência se dá menos para fazer justiça e desagravar as ofensas do que para - na condição de vingador e aplicador de força - provar que "até mesmo os fracos e pobres podem ser terríveis"( HOBSBAWM, 1976,p.54). Neste sentido, do ponto de vista dos valores sertanejos e da

\footnotetext{
${ }^{20}$ QUEIROZ, Renato da Silva. “Matraga, seu pai, seu filho”. Artigo disponível em http://www.imaginário.com.br.
} 
reivindicação do oprimido, a trajetória dos dois personagens traça uma linha ascendente, oposta às suas respectivas posições de origem.

Os atributos de valentia e destemor com que são agora configurados e reconhecidos socialmente na versão de Sariema, dispondo-os a enfrentar em luta de vida ou morte o antigo adversário, contrasta com a imagem de tibieza demonstrada diante do outrora todo poderoso fazendeiro, antes de sua desonrosa queda como Matraga, no relato anterior. Em contrapartida, o destino final de Matraga impede a sua trajetória rumo à renúncia propiciada pelo misticismo, alternativa por ele escolhida na novela para rejeitar a vingança e a ordem social, deslocando a vendeta para o plano cósmico.

No conto, ao reincidir no vício, na violência e no desregramento sexual (“Começou a beber umas cachaças, a descer os olhos pras minhas partes" - PR, p. 162), culminando com o estupro da narradora-protagonista, o personagem interrompe seu caminho em direção à espiritualização. Sua morte adquire consequentemente um sentido totalmente contrário ao do outro texto. Naquele, ele morre honrosamente lutando com seu Joãozinho Bem-Bem, chefe da jagunçagem, em quem reconhece um "irmão", portanto um igual, cujos predicados relativos à profissão que exerce desperta em Matraga uma identificação com a antiga imagem desregrada do todo poderoso representante da ordem vigente, Nhô Augusto (os dois extremos da estrutura coronelista se tocam). Neste, ele tem seu fim decretado por uma mulher, com quem é forçado a travar uma luta que considera ultrajante para sua condição de homem. Em “A hora e vez...", a luta é motivada por uma causa nobre: a defesa do oprimido - a família de um velho pobre do arraial do Rala Côco, em quem seu Joãozinho deseja vingar o assassinato de um dos seus jagunços, cometido pelo filho do ancião, que fugira.

Em "Sariema", o combate se dá por uma razão torpe: o estupro, como já foi dito. No primeiro caso, o último rito de passagem que encerra a tortuosa biografia do protagonista termina com a sua "santificação", decretada pelo grato pai da família salva por Matraga: "- Traz meus filhos, para agradecerem a ele, para beijarem os pés dele!... Não deixem este santo morrer assim...” ( $S$, p. 364). No segundo caso, morre como vilão, sob os impropérios da nova heroína, que antes de dar o derradeiro e violento golpe de misericórdia no adversário expressa sua raiva de outros tempos, uma antiga raiva guardada, apelando para a desqualificação social do inimigo: "filho de uma égua" (PR, p. 167). De gloriosa, a morte se torna ultrajante, de redentora, punitiva. É chegada a hora e vez de Sariema, complementarmente avessa à de Matraga.

Se como diz Maria Laura Muller (2005), seguindo aqui outros intérpretes da obra, “"A hora e vez de Augusto Matraga' é uma história de redenção e espiritualização, uma história de conversão", a versão contada por Sariema redireciona essa trajetória, faz com que ela passe a ser 
uma história de reinserção na violência, no crime e no "pecado". Uma história, portanto, não de passagem do mal ao bem, da perdição à salvação, para conservar aqui os mesmos termos empregados pela ensaísta ao percurso do protagonista na novela de Guimarães Rosa, mas uma história do reencontro de Matraga com sua antiga máscara social: Nhô Augusto, de quem é afinal a imagem às avessas. Uma história, sobretudo, de um ajuste de contas, anos depois, de uma vítima com seu agressor, de uma antiga prostituta com o antigo fazendeiro responsável pelo seu ultraje público num leilão de santo, no arraial do Murici. E também pela sua desonra no povoado do Tombador, onde finalmente se reencontram e se confrontam, sob novas máscaras, a de jagunça e a de "beato" em exercício de purgação e remissão dos pecados, para fechar o ciclo de suas trajetórias aberto pelo narrador do texto de Sagarana. Optando pela alternativa inversa a que Matraga escolheu para si na narrativa de referência, a de renunciador em contraposição à de vingador, a mulher, transmudada em "bandido social", interrompe a escolha do protagonista de Guimarães Rosa, desviando, no desfecho do conto, o exemplar traçado final da novela, para um outro traçado também exemplar, porém com nova e oposta significação. ${ }^{26}$

Segundo Foucault, "as fronteiras de um livro nunca são bem definidas: por trás do título, das primeiras linhas e do último ponto final, por trás de sua configuração interna e de sua forma autônoma, ele fica preso num sistema de referências a outros livros, outros textos, outras frases: é um nó dentro de uma rede" (FOUCAULT, apud Hutcheon, 1991, p.163). O conto de Rinaldo de Fernandes que acabamos de ler em correlação com a obra de João Guimarães Rosa atesta exemplarmente essa intrincada rede de referencialidade intertextual. Poder-se-ia dizer inclusive que faz dela a sua razão de ser, assumindo a intertextualidade como "a própria condição da textualidade" (HUTCHEON, 1991, p.167).

Pelo jogo lúdico da incorporação textual, "Sariema" exercita a arte de recriar um autor moderno de forte impacto e ampla repercussão no âmbito da literatura brasileira e latino-americana, induzindo a que se retome aqui a distinção teórica de Barthes entre textos legiveis e textos escrevíveis. Para o ensaísta de $S / Z$, os segundos se distinguiriam dos primeiros (os textos clássicos por excelência, organizados segundo um modelo representacional fechado, responsável pelo

\footnotetext{
${ }^{26} \mathrm{O}$ confronto entre os dois textos possibilita, assim, que se leia, aqui, a atualização de duas vias alternativas por onde se pode realizar - segundo ainda os subsídios teóricos de MATTA, 1979., pp. 258-259 - a rejeição do sistema social pelo indivíduo: a via ambígua da violência, onde a rejeição é parcial e termina por reproduzir a regra do próprio sistema (caso de Sariema no conto de Rinaldo), e a via da renúncia, via misticismo, forma mais radical de apartamento da ordem estabelecida, pelo deslocamento da vingança para o "outro mundo" (caso de Matraga, na novela de Guimarães Rosa). Afinal, como diz Mary Douglas (apud QUEIROZ. Op. cit., p. 2): "a santidade é a condição daqueles que são postos à parte". A representação ficcional dessas duas vias é recorrente na literatura brasileira que tematiza os fenômenos do messianismo e do cangaço ou enfoca a figura do jagunço. Ver a propósito, para citar apenas um exemplo, os romances Pedra Bonita (1938) e Cangaceiros (1953), de José Lins do Rego, onde essas duas vias se bifurcam, não estando o caminho místico, o sagrado, dissociado da violência.
} 
condicionamento passivo, burguês, do leitor), por incitar à práxis da escritura. Os textos escrevíveis, ao contrário, portanto, dos legíveis, aqueles que podem ser lidos, mas não reescritos, pautam-se por um modelo produtor, que induz o leitor a reescrevê-los, a deixar sua postura passiva de mero consumidor para lançar-se ele também como produtor de textos. Os textos escrevíveis/reescrevíveis, como os de Guimarães Rosa, suscitam em outros escritores o desejo de apropriação e resignificação daqueles de que se apropria, através de uma malha intertextual discursiva, que passa a se configurar como práxis paródica. Não paródia no sentido unilateral de "contracanto", mas também no de "canto paralelo", na redefinição do conceito bakhtiniano proposto por Linda Hutcheon, resgatando - nas suas reflexões sobre a metaficção historiográfica e as produções culturais, artísticas e literárias do pós-modernismo - a etimologia ambivalente do termo: "A importância coletiva da prática paródica (no contexto do pós-modernismo) sugere uma redefinição da paródia como uma repetição com distância crítica que permite a indicação irônica da diferença no próprio âmago da semelhança. (...) Essa paródia realiza paradoxalmente tanto a mudança como a continuidade cultural: o prefixo grego para - pode tanto significar 'contra' como 'perto' ou 'ao lado". 'Trata-se, portanto, de uma reescritura paradoxal e ambígua, simultaneamente reverente e transgressora face ao texto original: "paródia de dois gumes" (HUTCHEON, 1991, p.165).

A ficção brasileira contemporânea - para localizar a questão apenas entre nós - tem recorrido a essa prática paródica como estratégia de diálogo com as obras antecessoras, distinguidas metaficcionalmente como textos (re)escrevíveis. Situa-se nessa relação dialógica a retomada, na década de setenta, do célebre conto de Machado de Assis, "Missa do galo", por seis renomados representantes da contística e do romance nacionais (Antonio Callado, Autran Dourado, Julieta de Godoy Ladeira, Lygia Fagundes Telles, Nélida Piñon e Osman Lins), que de uma perspectiva mais ou menos próxima ou distante do modelo, de ângulos inusitados e recortes diferentes, adotando o ponto de vista deste ou daquele personagem, iluminaram os aspectos sombrios e lacunares, as ambiguidades estéticas e ideológicas, em suma, o dito e o não-dito da tessitura machadiana para compor suas "variações sobre o mesmo tema"32. Chama a atenção, sobretudo, pela coincidência com a perspectiva do conto de Rinaldo, a tomada de posição de Julieta de Godoy Ladeira em prol da personagem feminina, “a boa Conceição", que, convertida em narradora do relato, em substituição à figura masculina do conto, Nogueira, desmonta a versão do narrador machadiano acerca de seu papel de mulher deserotizada, passiva, submissa e conivente com as escapadelas noturnas e metódicas do marido para se encontrar com a amante.

32 CALLADO, Antonio et all. Missa do galo (de Machado de Assis): variagõés sobre o mesmo tema. São Paulo: Summus, 1977. 
Pode-se citar, também, em fins dos anos oitenta, a tradução romanesca dos eventos de Canudos e consequentemente de seu intérprete maior, Euclides da Cunha, por J. J. Veiga em $A$ casca da serpente (1989), que reedita, sob uma perspectiva crítica, não só os acontecimentos do arraial de Antônio Conselheiro, relatados em Os sertões, mas também a imagem do próprio condutor espiritual da comunidade messiânica, transmudado de líder teocrata, autoritário e conservador, voltado para o mundo endógeno e para a tradição ${ }^{34}$ sertaneja, a liberal democrata, aberto às inovações da ciência e ao progresso do mundo exógeno, sob a nova roupagem identitária de Tio Antônio ${ }^{35}$.

E, finalmente, para elencar apenas mais um exemplo dentre tantos outros, a recriação paródica, na década de noventa e nos primeiros anos do século XXI, de um outro texto do romancista fluminense, Dom Casmurro, e da fortuna crítica do autor, pelos contos de Dalton Trevisan, "Capitu sem enigma” (1994) e "Capitu sou eu” (2003) ${ }^{36}$, seja pela recontextualização atual da controvertida questão do adultério feminino, via glosa irônica do tema, ou da polêmica recepção da obra, seja focalizando a também controversa identidade da protagonista, forjada numa fabulação a posteriori, pela imaginação ciumenta do narrador, como bem demonstra em recente ensaio Moema Selma D'Andrea. ${ }^{37}$

Tais recorrências recontextualizadas num outro texto deslocam o foco da discussão teórica da relação autor-texto para o da relação texto-leitor, motivando também o questionamento do conceito imanentista de originalidade e valor estético, segundo diz ainda Linda Hutcheon, referindo-se à redefinição do conceito de intertextualidade por Barthes e Rifaterre:

Conforme Barthes (...) e Rifaterre (...) a definiram (...) a intertextualidade substitui o relacionamento autor-texto, que foi contestado, por um relacionamento entre o leitor e o texto, que situa o locus do sentido textual dentro da história do próprio discurso. Na verdade, uma obra literária já não pode ser considerada original; se o fosse não poderia ter sentido para seu leitor. Ė apenas como parte de discursos anteriores que qualquer texto obtém sentido e importância. (HUTCHEON, 1991, p. 166)

Leitor ativo de Guimarães Rosa, Rinaldo de Fernandes - assim como J. J. Veiga na sua leitura de Euclides da Cunha, Dalton Trevisan e os autores que concretizaram o projeto coletivo de reescrever "Missa do galo" (arquitetado por Osman Lins), nas suas respectivas retomadas da

\footnotetext{
${ }^{34}$ Sobre a articulação entre tradição/tradução ver HALL, Stuart. "A identidade cultural na pós-modernidade". Trad. de Tomas Tadeu da Silva e Guaracira Lopes Lauro. Rio de Janeiro: DP\&A, 2002, p. 81.

${ }^{35}$ Cf. FARIAS, Sônia Lúcia Ramalho de. "Canudos revisitado pela ficção". In: ___e LEITE, João Denys Araújo (orgs). Imagens do Brasil na Literatura. Recife: Programa de Pós-Graduação em Letras da UFPE, 2005, pp. 99-123.

${ }^{36}$ Publicados respectivamente em TREVISAN, Dalton. Dinorá: novos mistérios. Rio de Janeiro: Record, 1994, pp. 2936; _. Capitu sou eu. Rio de Janeiro: São Paulo, 2003, pp. 7-18.

${ }^{37}$ D’ANDREA, Moema Selma. “Capitu sou eu ou é ela? Afinal quem é Capitu?”. In: Graphos: revista da Pós-Graduacãa em Letras (UFPB). João Pessoa: Ideia, v. 6, nº 2/1, 2004, pp. 17-21.
} 
obra do "bruxo de Cosme Velho" - reformula, com significativas mudanças, o sentido da escritura primeira, atestando também, como defende uma das vertentes da teoria literária contemporânea, que o significado de uma dada obra só se atualiza pelo contexto histórico de sua recepção.

No caso específico de "Sariema", o locus contextual em que se insere, o da chamada "pósmodernidade" ou pós-modernismo, como prefere Linda Hutcheon, enseja que se repense os conceitos de centro e periferia, que se revejam as questões ligadas a etnia, raça e sexo, que se reformulem valores identitários. Respondendo pelo artifício fingido da ficção a esse solo históricocultural, o conto em pauta desloca, através da fala de sua protagonista feminina, o centro, as margens e as extremidades da novela em que se inspira, dando a eles um novo valor. Resulta desse processo construtivo uma singular (não "original") escritura que, ao inserir e subverter, ao mesmo tempo, a novela de Rosa, inspirado, de certa forma, em outro modelo rosiano, o do romance do autor, incorpora, via "paródia de dois gumes", a diferença na semelhança. E assume, simultaneamente, uma postura fiel e traiçoeira, uma "relação dialógica entre a identificação e a distância" (HUTCHEON, 1991, p.58), uma fidelidade transgressora face à sua matriz. Realiza, em resumo, um jogo escritural de sedução entre seu texto e o intertexto de Guimarães Rosa.

\section{REFERÊNCIAS:}

BENJAMIN, Walter. “O narrador, observações acerca da obra de Nicolau Lescov”. In: Magia e técnica, arte e política: ensaios sobre literatura e história da cultura. Trad. Sérgio Paulo Rouanet. $2^{\text {a }}$ ed. São Paulo: Brasiliense, 1986.

CANDIDO, Antonio. "Sagarana”. In: COUTINHO, Eduardo. (org). Guimarães Rosa. $2^{a}$ ed. Rio de Janeiro: José Olympio, 1991.

COUTINHO, Eduardo. Nota preliminar. In: (org). Guimarães Rosa. $2^{\text {a }}$ ed. Rio de Janeiro: José Olympio, 1991.

FERNANDES, Rinaldo de. O perfume de Roberta (contos). Rio de Janeiro: Garamond, 2005.

GALVÃO, Walnice Nogueira. "A linguagem e a fala”. In: As formas do falso. São Paulo: Perspectiva, 1972.

HOBSBAWM, E. J. Bandidos. $2^{\mathrm{a}}$ ed. Trad. de Donaldson Magalhães Garschagen. Rio de Janeiro: Forense Universitária, 1976.

HUTCHEON, Linda. Poética do pós-modernismo: história, teoria, fição. Trad. de Ricardo Cruz. Rio de Janeiro: Imago, 1991.

LINS, Álvaro. Uma grande estreia. In: COUTINHO, Eduardo. (org). Guimarães Rosa. $2^{a}$ ed. Rio de Janeiro: José Olympio, 1991. 
MATTA, Roberto da. “Augusto Matraga e a hora da renúncia”. In: Carnavais, malandros e heróis: para uma sociologia do dilema brasileiro. Rio de Janeiro: Zahar, 1979.

MULLER, Maria Laura. "A hora e vez de Augusto Matraga". Disponível em: www.portasdasletras.com.br. Acesso em 29/10/2005.

SCHWARZ, Roberto. "Grande-sertão: a fala". In: A sereia e o desconfiado: ensaios críticos. $2^{a}$ ed. Rio de Janeiro: Paz e Terra, 1981. 